\title{
The Effects of Educational Interventions on Nurses' Knowledge and Practices in Hemodialysis Unit Regarding Infection Control Practices
}

Fatma Korashy Osman*, Haneya Mohamed El Banna, Amany Youssef Sharaf, Yasmin Fathy Mohammed

Medical Surgical Nursing Department, Faculty of Nursing, Alexandria University, Egypt

*Corresponding author: Fatma Korashy Osman, Mobile: (+20) 01113532059, E-Mail: fatykorashy1234@gmail.com

\begin{abstract}
Background: Nurses are considered a key element to break the chain of the infection through their adherence to standard precautions. Many factors may hinder nurses' adherence to these precautions as; shortage of nurses, high number of patient ratio, turn-over of nursing staff, lack of staff training, inadequate supplies, patient urgency, time limits and low patients education level regarding infection control.

Objective: This study aims to evaluate the effects of educational interventions on nurses' knowledge and practices in Hemodialysis Unit regarding infection control practices.

Patients and methods: A quasi-experimental research design (pretest-posttest) was utilized to fulfill the aim of the study. The study was conducted at the Hemodialysis Unit, Alexandria Fever Hospital. All nurses who were involved in providing direct care throughout the three shifts (morning, evening, night), for patients, at the above-mentioned setting, were included in the study ( $\mathrm{n}=30$ nurses).

Results: No statistical significant relationships were detected between the studied nurses' knowledge levels and their demographic characteristics after application of the educational interventions. Statistical significant relationships were detected between the nurses' age, level of education, and their practices level after application of the educational interventions. The results of the present study highlighted that nearly two thirds of the studied nurses had "poor" overall knowledge and half of them had "poor" overall practices regarding infection prevention, and control practices before application of the educational interventions.

Conclusion: Educational nursing interventions had significant positive effects on overall percent improvement of nurses' knowledge, and practice related to infection control in Hemodialysis (HD) Unit Fever Hospital.

Keywords: Educational Interventions, Hemodialysis Unit, Infection Control Practices, Nurses' Knowledge and Practices.
\end{abstract}

\section{INTRODUCTION}

End-stage renal disease (ESRS) is a health issue that extends worldwide as it requires long term care and in the same time, is very costly. Prevalence of chronic renal failure increases in various countries (1).

The annual incidence of ESRD in Egypt (2015) was about 74 per million populations (pmp), and the prevalence of patients on dialysis was 264 per million populations (pmp). ESRD of hospitalized patients was around $1.68 \%$ of all hospitalized Egyptian patients. Egypt is highlighted as the first country which has the highest rate of mortality of patients with renal failure, as $25 \%$ of ESRD patients die annually ${ }^{(2)}$.

Patients' quality of life has improved by hemodialysis (HD) therapy, but patients treated with hemodialysis are at increased risk of infection firstly due to the hemodialysis process itself, secondly hemodialysis patients are immunosuppressed, and require frequent blood transfusions and hospitalizations which expands their chances for hospital-acquired infections ${ }^{(3)}$.

Infection is considered the main reason for hospitalization and the second cause for mortality in HD patients ${ }^{(4)}$. Poor adherence to infection control practices by healthcare personnel (HCP) is the primary reasons for incidence of infection, so consistent and strict adherence to rules of standard precautions by the (HCP) is assumed to be a noteworthy role in controlling such infection ${ }^{(5)}$.

Nurses are the cornerstone of managing HD patients safely in health care settings. They have an essential role in breaking the chain of infection through compliance with infection prevention and control practices. Unfortunately, sometimes nurses utilize optional approaches of the infection prevention and control practices ${ }^{(6)}$. Constant training programs must be made by the health care settings to apply evidence based practices to prevent and control infection. These programs must consist of theoretical and practical area to enhance nurses' adherence to infection prevention and control practices ${ }^{(7)}$.

The Center of Disease Control (CDC) developed a staff training program in 2016 to maintain safe dialysis and zero infection in HD units.

This program consisted of: hand hygiene, AV care, safe injection, use of personal protective equipment (PPE), and cleaning, disinfection of dialysis station. It also included the use of checklists, month to month reviews of hand hygiene practices just for prescribing the adherence of nursing staff related to infection prevention and control practices. Later on the results of these checklists were used to enhance staff adherence ${ }^{(8,9)}$. 


\section{Significance of the study:}

The incidence and prevalence rates of patients treated by HD are increasing. The mortality rates among patients on hemodialysis is higher than other diseases ${ }^{(\mathbf{1 0})}$. Although infection is the second cause of mortality in HD patients, it has been assumed that HD nurses' adherence to infection perevention and control practices is poor ${ }^{(4)}$. As one of the nursing goals is to maintain HD patient safety, so nurses need be equipped with periodic educational interventions that supply them with the required knowledge and skills to improve their patient's quality of care and prevent infection ${ }^{(11)}$.

The present study aimed to evaluate the effects of educational intervention on nurses' knowledge and practices regarding infection prevention and control practices among nursing staff working at the HD Unit at Alexandria Fever Hospital.

\section{SUBJECTS AND METHOD}

Design: A quasi-experimental research design (pretest-posttest) was utilized to fulfill the aim of the study.

Setting: The study was conducted at the Hemodialysis Unit, Alexandria Fever Hospital. This unit is composed of two rooms for virus free patients who are on maintenance HD, which contain"18" dialysis machines. There are other three rooms for isolation of infected patients who are (HBV, HCV, HIV) viruses positive and, contain five, seven, and two dialysis machines respectively. Another room is available for emergency cases, which contains two dialysis machines, for "non $\mathrm{C}$ " virus patients.

Subjects: All nurses who were involved in providing direct care throughout the three shifts (morning, evening, night), for patients, at the above-mentioned setting, were included in the study ( $\mathrm{n}=30$ nurses).

\section{Tools of the study:}

Two tools were developed by the researcher to fulfill the aim of the study:

\section{Tool I: Hemodialysis Nurses' Infection Prevention and Control Practices Knowledge Questionnaire:}

This tool is a structured interview schedule that was developed by the researcher based on a thorough review of recent related literature. It was utilized to assess nurses' knowledge regarding infection prevention and control practices. It included two parts as follows:

Part I: This part included nurses' sociodemographic characteristics as: age, gender, level of education, marital status, years of experience in the dialysis units, attendance of pre and in-service training programs regarding infection prevention and control.

Part II: This part included a group of open, and closed ended questions to assess nurses' knowledge related to the following domains with its sub "practices" or "competencies" ${ }^{(\mathbf{8 , 9}, \mathbf{1 2}, \mathbf{1 3})}$ :

a) Blood borne infection.

b) Hand hygiene.

c) Personal protective equipment.

d) Cleaning and disinfection of environmental surfaces.

e) Cleaning and disinfection of external surfaces of HD machines.

f) Disinfection of the internal fluid pathway of hemodialysis machines.

g) Handling of disposable supplies and reusable items in HD units.

h) Water treatment.

i) Safe injection practices:

- Safe preparation of medication.

- Safe administration of medication.

j) Vascular access: care and prevention of infection.

k) Screening/routine serologic testing and patient placement.

1) Immunization of patients and health-care personnel.

Nurses' knowledge answers to each competency were scored on a three-point likert scale as follows:

- Two score were allotted for "correct and complete response".

- One score was allotted for "correct and incomplete response".

- Zero was allotted for "incorrect, and no answer".

\section{Scoring system:}

The scores obtained for each domain and all domains were summed up, and converted into percent scores as follows:

- $75 \%-100 \%$ scores were considered "good knowledge".

- From $50 \%$ - $<75 \%$ scores were considered "fair knowledge".

- Less than $50 \%$ scores were considered "Poor knowledge".

Tool II: Infection prevention and Control Practices: Nurses` Performance Observational Checklist.

This tool was developed based on CDC Guidelines ${ }^{(8)}$ as well as the WHO Bundle of Care (14). It was used to check nurses' performances against international ideal guidelines and standard, related to the following domains and its sub practices/competencies:

a) Hand hygiene.

b) Personal protective equipment.

c) Arteriovenous fistula/graft cannulation.

d) Arteriovenous fistula/graft decannulation.

e) Catheter exit site care.

f) Catheter connection and disconnection.

g) Hemodialysis injectable medication preparation. 
h) Hemodialysis injectable medication administration.

i) Hemodialysis station routine disinfection.

j) Cleaning and disinfection of external surfaces of HD machines.

k) Disinfection of the internal fluid pathway of HD machines.

1) Handling of disposable supplies and reusable items.

Each of the above-mentioned domains included sub practices/competencies that were checked and scored as follows:

"Correctly and completely done" "2", "incorrectly, and incompletely done" "1", and "not done" "0". Total nurses domains scores were calculated, then converted into mean percent score.

\section{Scoring system:}

- $\quad$ 75\% - $100 \%$ were considered "Good nurses' practice".

- From 50\% to $<75 \%$ were considered "Satisfactory nurses' practice".

- Less than 50\% were considered "Poor nurses' practice".

\section{Method:}

1) Tool I and Tool II were developed by the researcher after review of the related literature.

2) of the tools was tested by 5 experts in the fields of Medical Surgical Nursing, Faculty of Nursing and Infection Control Committee of the Fever Hospital, Alexandria and, the recommended modifications were introduced, accordingly.

3) A pilot study was carried out on $10 \%$ of the study sample (3 nurses), to test the feasibility, applicability of the tools and the necessary modifications were done.

4) Reliability of the tools was estimated using Cronbach's Alpha coefficient test. For Tool I $(\mathrm{r}=0.839)$ and for Tool II ( $\mathrm{r}=0.924)$.

5) To fulfill the study aim, the study was carried out, in four phases: assessment, planning (developing), implementation, and evaluation.

\section{Phase I: Assessment Phase:}

Initial assessment (pre-test) of the study nurses' knowledge and practices was carried out using tools I, II to develop the educational interventions based on nurses' assessment needs.

- Every participant nurse was watched individually, for her infection control (IC) practices, throughout performances of dialysis procedures of three patients, using tool II, (via concealed observations). The observations were carried out throughout the three morning, evening, and night shifts.

After completing all observations, the participant nurses were interviewed, to fill in the HD nurses' knowledge questionnaires using tool (I) after explaining the purpose of the study.

- The interviews were carried out throughout break hours, and the answers were recorded in the tool.

\section{Phase II: Planning (Developing) Phase:}

- The related educational interventions were developed by the researcher based on review of literature as well as the finding of the assessment phase. The developed educational interventions were translated into Arabic and revised by 5 experts in the fields of Medical Surgical Nursing and Infection Control Committee of the Fever Hospital, Alexandria. The necessary modifications were introduced accordingly.

- The educational interventions included essential information related to theoretical and practical as follows:

- Theoretical content of the educational intervention:

A. An overview session (chain of infection: definition, phases and how to break the chain of infection, blood borne infection: viral infection (HBV, HCV, HIV) and bacterial infection; multidrug resistant organisms (MDROs).

B. Infection prevention and control practices session (hand hygiene, personal protective equipment, safe injection practices, prevention of hemodialysis associated infections, water treatment, cleaning and disinfection of environment surface, disinfection of the internal fluid pathways of hemodialysis machines, waste management, sharps disposal, and linin management, Screening/routine serologic testing and patient placement, as well as immunization of patients and health-care personal).

- Practical content of the educational intervention: these contents covered the following main topics:

- Performance of proper hand hygiene.

- PPE.

- Cannulation and decannulation of arteriovenous fistula/ graft.

- Connection and disconnection of catheter.

- Care of catheter.

- Preparation and administration of hemodialysis injectable medication.

- Routine disinfection of hemodialysis station.

- Cleaning and disinfection of external surfaces of HD machines.

- Disinfection of the internal fluid pathway of hemodialysis machines.

- Handling of disposable supplies and reusable items in HD units.

Phase III: Implementation phase: (the nursing educational interventions). 
- Time schedule for implementation of the educational interventions was introduced to each participant nurse, before starting of the implementation phase.

- Based on the pretest results, the educational interventions were developed and delivered to nurse participants over four sessions. Each session included theoretical and practical information presented through demonstration, redemonstration and power point presentation. Sessions were conducted throughout nurses' break hours. Session duration varied according to work conditions, ranging from 30-45 minute.

\section{The educational interventions were submitted through four sessions:}

The initial two sessions were for theoretical area, and last two, were for practical content presentation.

\section{A. Theoretical content:}

- Session one: included information about blood borne infection, hand hygiene, PPE, cleaning and disinfection of environmental surfaces, cleaning and disinfection of external surfaces of HD machines, and disinfection of the internal fluid pathway of HD machines.

- Session two: included information about handling of disposable supplies and reusable items in HD units, water treatment, safe injection practices, vascular access care and prevention of infection, screening/routine serologic testing and patient placement, and of patients and health-care personal immunization.

\section{B. Practical area:}

○ Session three: consisted of six lessons: Performance of proper hand hygiene, PPE, cannulation and decannulation of arteriovenous fistula/graft, connection and disconnection of catheter, and care of catheter.

- Session four: consisted of six lessons: preparation and administration of hemodialysis injectable medication, routine disinfection of HD station, cleaning and disinfection of external surfaces of HD machines, disinfection of the internal fluid pathway of HD machines, and handling of disposable supplies and reusable items in HD units.

- Participants received clinical guided training for three days per week during dialysis procedures for two consecutive weeks.

- Group discussions, feedbacks and arising circumstances were considered.

- Printable version of the educational intervention was presented to all participants.

\section{Phase IV: Evaluation phase:}

- To determine the effectiveness of the educational interventions on HD nurses' knowledge and practices, posttest evaluation was carried out using tools (I) and (II) for every nurse twice to evaluate their knowledge and practices (immediately post the educational interventions implementation, and one month later).

- Nurses were watched for their practices, three times throughout the three morning, afternoon, and night shifts.

\section{Ethical considerations:}

A written approval letter to carry out the study was obtained from the Ethical Committee of the Faculty of Nursing, Alexandria University. An official letter to carry out the study was obtained from the administrative authorities of the study setting, after explanation of the aim of the study.

Written informed consent was obtained from head nurses. Written informed consent was obtained from nurses participating in the study, after explanation of the purpose of the study. Confidentiality and anonymity of data of HD nurse participants were maintained, throughout implementation of the study. Participant nurses were assured, they have the right to withdraw from the study at any time.

\section{Statistical analysis}

The collected data were coded, processed and analyzed using the SPSS (Statistical Package for the Social Sciences) version 22 for Windows ${ }^{\circledR}$ (IBM SPSS Inc, Chicago, IL, USA). Data were tested for normal distribution using the Shapiro Wilk test. Qualitative data were represented as frequencies and relative percentages. Chi square test $\left(\chi^{2}\right)$ was used to calculate difference between two or more groups of qualitative variables. Quantitative data were expressed as mean $\pm \mathrm{SD}$ (Standard deviation) and range. Independent samples t-test was used to compare between two independent groups of normally distributed variables (parametric data). $\mathrm{P}$ value $<0.05$ was considered significant.

\section{RESULTS}

Table 1 shows that the highest percentage of the studied nurses was in the age group of 30 years. The majority of the studied nurses were bachelor degree graduates and married.

For years of experience: the table reveals that more than half of the studied nurses had 10 years of experience, and the majority of them attended programs related to infection prevention and control, which were mainly received from the Infection Prevention Control Committee of the Fever Hospital, Alexandria. 
Table (1): Distribution of the studied nurses according to their sociodemographic characteristics $(\mathrm{n}=30)$.

\begin{tabular}{|c|c|c|}
\hline \multirow{2}{*}{ Sociodemographic characteristics of the studied nurses. } & \multicolumn{2}{|c|}{ Total $\mathbf{n}=\mathbf{3 0}$} \\
\hline & No. & $\%$ \\
\hline \multicolumn{3}{|l|}{ Age (years) } \\
\hline$-20-$ & 7 & 23.3 \\
\hline$-30-$ & 13 & 43.3 \\
\hline$-40-$ & 6 & 20.0 \\
\hline$-\geq 50$ & 4 & 13.4 \\
\hline $20-55$ & & \\
\hline \multicolumn{3}{|l|}{$37.33 \pm 9.551$} \\
\hline \multicolumn{3}{|l|}{ Level of education } \\
\hline - Diploma of Secondary School of Nursing & 1 & 3.4 \\
\hline - Diploma of Technical Institute of Nursing & 4 & 13.3 \\
\hline - Bachelor Degree of Nursing & 25 & 83.3 \\
\hline \multicolumn{3}{|l|}{ Marital status } \\
\hline - Single & 4 & 13.3 \\
\hline - Married & 22 & 73.3 \\
\hline - Widowed & 2 & 6.7 \\
\hline - Divorced & 2 & 6.7 \\
\hline \multicolumn{3}{|l|}{ Years of experience } \\
\hline$-<5$ & 3 & 10.0 \\
\hline$-5-$ & 5 & 16.7 \\
\hline$-10-$ & 18 & 60.0 \\
\hline$-\geq 15$ & 4 & 13.3 \\
\hline Min - Max & & \\
\hline $\begin{array}{lr}\text { Mean } \pm \text { SD } & 11.33 \pm 4.017 \\
\end{array}$ & & \\
\hline \multicolumn{3}{|l|}{ Attendance of training workshops about infection control } \\
\hline - Yes & 25 & 83.3 \\
\hline - No & 5 & 16.7 \\
\hline $\begin{array}{l}\text { Who carried out the training program(s) about infection } \\
\text { prevention and control }\end{array}$ & \multicolumn{2}{|c|}{$n=25$} \\
\hline $\begin{array}{l}\text { - Head nurse } \\
\text { - Colleagues } \\
\text { - Others (Infection Control Committee of the Fever Hospital, } \\
\text { Alexandria) }\end{array}$ & $\begin{array}{c}7 \\
9 \\
14\end{array}$ & $\begin{array}{l}28.0 \\
16.0 \\
56.0\end{array}$ \\
\hline
\end{tabular}

More than half of the studied nurses had "poor" level of knowledge before application of the educational interventions. The majority of the studied nurses achieved "good" level of knowledge, immediately and one month after application of the educational interventions. Table 2 also represents that, the overall percent score of the studied nurse's knowledge improved significantly after application of the educational interventions immediately and one month later. 
Table (2): Differences in the studied nurses overall knowledge regarding infection prevention and control practices pre, immediately after and one month post application of the educational interventions $(n=30)$.

\begin{tabular}{|c|c|c|c|c|c|c|c|c|c|}
\hline \multirow{4}{*}{$\begin{array}{c}\text { Nurses level of } \\
\text { overall knowledge }\end{array}$} & \multirow{3}{*}{\multicolumn{2}{|c|}{$\begin{array}{c}\text { Pre } \\
\text { interventions }\end{array}$}} & \multirow{2}{*}{\multicolumn{4}{|c|}{ After interventions }} & \multicolumn{3}{|c|}{ Test of sig. } \\
\hline & & & & & & & P1 & $\mathbf{P 2}$ & P3 \\
\hline & & & \multicolumn{2}{|c|}{ Immediately } & \multicolumn{2}{|c|}{$\begin{array}{c}1 \text { month } \\
\text { post- } \\
\text { interventions }\end{array}$} & \multirow[t]{2}{*}{ S $\underset{\substack{\text { Pre/ } \\
\text { post }}}{\text { Immediately }}$} & \multirow[t]{2}{*}{$\begin{array}{c}\text { Pre/ } 1 \text { month. } \\
\text { post }\end{array}$} & \multirow[t]{2}{*}{$\begin{array}{c}\text { Immediately } \\
\text { one month }\end{array}$} \\
\hline & No. & $\%$ & No. & $\%$ & No. & $\%$ & & & \\
\hline Poor & 19 & 63.3 & 0 & 0.0 & 0 & 0.0 & \multirow{5}{*}{$\begin{array}{c}\mathrm{X}^{2 \mathrm{~b}}=53.23 \\
\mathrm{P}=0.000^{*}\end{array}$} & \multirow{5}{*}{$\begin{array}{l}X^{2 c}=53.23 \\
P=0.000^{*}\end{array}$} & \multirow{5}{*}{$\begin{array}{c}X^{2 d}=----- \\
P=----\end{array}$} \\
\hline Fair & 11 & 36.7 & 2 & 6.7 & 2 & 6.7 & & & \\
\hline Good & 0 & 0.0 & 28 & 93.3 & 28 & 93.3 & & & \\
\hline $\begin{array}{l}\text { Total score } \\
\text { Min. - Max. } \\
\text { Mean } \pm \text { SD. }\end{array}$ & \multicolumn{2}{|c|}{$\begin{array}{c}24.00-62.00 \\
43.83 \pm 8.655\end{array}$} & \multicolumn{2}{|c|}{$\begin{array}{r}70.00-84.00 \\
78.27 \pm 3.237\end{array}$} & \multicolumn{2}{|c|}{$\begin{array}{l}70.00-84.00 \\
78.27 \pm 3.237\end{array}$} & & & \\
\hline $\begin{array}{l}\text { \% score } \\
\text { Min. - Max. } \\
\text { Mean }\end{array}$ & \multicolumn{2}{|c|}{$\begin{array}{c}26.9-67.39 \\
4764\end{array}$} & \multicolumn{2}{|c|}{$\begin{array}{c}76.09-91.30 \\
85.08\end{array}$} & \multicolumn{2}{|c|}{$\begin{array}{c}76.09-91.30 \\
85.08\end{array}$} & & & \\
\hline
\end{tabular}

$\mathrm{X}^{2}$ Chi Square Test.

$\mathrm{X}^{2 \mathrm{~b}}$ Comparison between the pre intervention and immediately after intervention.

$\mathrm{X}^{2 \mathrm{c}}$ Comparison between the pre intervention and 1 month post.

$\mathrm{X}^{2 \mathrm{~d}}$ Comparison between immediately after intervention and 1 month post.

* Statistically significant at $\mathrm{p} \leq 0.05$

Half of the studied nurses had "poor" level of practice before application of the educational interventions. The majority of the studied nurses achieved "good" level of practice immediately, and one month post application of the educational interventions. The overall percent score of the studied nurses improved significantly after application of the educational interventions immediately, and one month later.

Table (3): Differences in the studied nurses' practices regarding infection prevention and control practices pre, immediately after, and one month post application of the educational interventions $(n=30)$

\begin{tabular}{|c|c|c|c|c|c|c|c|c|c|}
\hline \multirow{4}{*}{$\begin{array}{l}\text { Nurses } \\
\text { level of } \\
\text { practices }\end{array}$} & \multirow{3}{*}{\multicolumn{2}{|c|}{$\begin{array}{c}\text { Pre } \\
\text { interventions }\end{array}$}} & \multirow{2}{*}{\multicolumn{4}{|c|}{ After interventions }} & \multicolumn{3}{|c|}{ Test of sig. } \\
\hline & & & & & & & \multirow{3}{*}{$\begin{array}{c}\text { p1 } \\
\text { Pre/ } \\
\text { Immediately } \\
\text { post }\end{array}$} & \multirow{3}{*}{$\begin{array}{c}\text { P2 } \\
\text { Pre/ } \\
1 \text { month. } \\
\text { post }\end{array}$} & \multirow{3}{*}{\begin{tabular}{|c|} 
P3 \\
Immediately/ \\
1 month. \\
post
\end{tabular}} \\
\hline & & & \multicolumn{2}{|c|}{ Immediately } & \multicolumn{2}{|c|}{$\begin{array}{l}1 \text { month post- } \\
\text { interventions }\end{array}$} & & & \\
\hline & No. & $\%$ & No. & $\%$ & No. & $\%$ & & & \\
\hline Poor & 15 & 50 & 0 & 0.0 & 0 & 0.0 & \multirow{5}{*}{$\begin{array}{l}X^{2 b}=42.86 \\
P 1=0.000^{*}\end{array}$} & \multirow{5}{*}{$\begin{array}{l}X^{2 c}=42.86 \\
P 2=0.000^{*}\end{array}$} & \multirow{5}{*}{$\begin{array}{c}X^{2 \mathrm{~d}}=------ \\
P=----\end{array}$} \\
\hline Fair & 15 & 50 & 6 & 20 & 6 & 20 & & & \\
\hline Good & 0 & 0.0 & 24 & 80 & 24 & 80 & & & \\
\hline $\begin{array}{l}\text { Total score } \\
\text { Min. - Max. } \\
\text { Mean } \pm \text { SD. }\end{array}$ & \multicolumn{2}{|c|}{$\begin{array}{c}153.00-202.67 \\
176.49 \pm 13.56\end{array}$} & \multicolumn{2}{|c|}{$\begin{array}{c}246.67-315.00 \\
278.73 \pm 16.89\end{array}$} & \multicolumn{2}{|c|}{$\begin{array}{l}246.67-315.00 \\
278.73 \pm 16.89\end{array}$} & & & \\
\hline $\begin{array}{l}\text { \% score } \\
\text { Min. - Max. } \\
\text { Mean }\end{array}$ & \multicolumn{2}{|c|}{$\begin{array}{c}42.74-56.61 \\
49.58\end{array}$} & \multicolumn{2}{|c|}{$\begin{array}{c}68.90-87.99 \\
78.29\end{array}$} & \multicolumn{2}{|c|}{$\begin{array}{c}68.90-87.99 \\
78.29\end{array}$} & & & \\
\hline
\end{tabular}

$\mathrm{X}^{2}$ Chi Square Test.

$\mathrm{X}^{2 \mathrm{~b}}$ Comparison between the pre intervention and immediately after intervention.

$\mathrm{X}^{2 \mathrm{c}}$ Comparison between the pre intervention and 1month post.

$\mathrm{X}^{2 \mathrm{~d}}$ Comparison between immediately after intervention and1 month post. .

* Statistically significant at $\mathrm{p} \leq 0.05$

Regarding the nurse's level of knowledge, it had no statistical significant relationship with age, nurses' level of education, years of experience, and training about infection prevention and control. 
Table (4): Relationships between the studied nurses' knowledge levels and their demographic characteristics after application of the educational interventions (immediately, one month later)

\begin{tabular}{|c|c|c|c|c|c|c|c|c|c|c|}
\hline \multirow{5}{*}{$\begin{array}{l}\text { Sociodemographic } \\
\text { characteristics }\end{array}$} & \multicolumn{8}{|c|}{ Nurses' level of knowledge post intervention } & \multirow{2}{*}{\multicolumn{2}{|c|}{ Test of significance }} \\
\hline & \multicolumn{4}{|c|}{ Immediately } & \multicolumn{4}{|c|}{ One month later } & & \\
\hline & Fair & & \multirow{2}{*}{\multicolumn{2}{|c|}{$\begin{array}{c}\text { Good } \\
(\mathbf{N}=\mathbf{2 4})\end{array}$}} & \multirow{2}{*}{\multicolumn{2}{|c|}{$\begin{array}{l}\text { Fair } \\
(N=6)\end{array}$}} & \multirow{2}{*}{\multicolumn{2}{|c|}{$\begin{array}{c}\text { Good } \\
(\mathrm{N}=24)\end{array}$}} & \multirow{3}{*}{$\mathbf{P 1}$} & \multirow{3}{*}{$\mathbf{P 2}$} \\
\hline & \multicolumn{2}{|c|}{$(\mathrm{N}=6)$} & & & & & & & & \\
\hline & No. & $\%$ & No. & $\%$ & No. & $\%$ & No. & $\%$ & & \\
\hline \multicolumn{11}{|l|}{ Age } \\
\hline $20-$ & 1 & 14.3 & 6 & 85.7 & 1 & 14.3 & 6 & 85.7 & \multirow{4}{*}{$\begin{array}{l}X^{2}=2.832 \\
P=0.418\end{array}$} & \multirow{4}{*}{$\begin{array}{l}X^{2}=2.832 \\
P=0.418\end{array}$} \\
\hline $30-$ & 0 & 0 & 13 & 100 & 0 & 0 & 13 & 100 & & \\
\hline $40-$ & 1 & 16.7 & 5 & 83.3 & 1 & 16.7 & 5 & 83.3 & & \\
\hline$\geq 50$ & 0 & 0 & 4 & 100 & 0 & 0 & 4 & 100 & & \\
\hline \multicolumn{11}{|l|}{ Level of education } \\
\hline Technical secondary school & 0 & 0 & 1 & 100 & 0 & 0 & 1 & 100 & \multirow{3}{*}{$\begin{array}{l}X^{2}=2.518 \\
P=0.284\end{array}$} & \multirow{3}{*}{$\begin{array}{l}X^{2}=2.518 \\
P=0.284\end{array}$} \\
\hline Technical institute & 1 & 25 & 3 & 75 & 1 & 25 & 3 & 75 & & \\
\hline Bachelor of nursing & 1 & 4 & 24 & 96 & 1 & 4 & 24 & 96 & & \\
\hline \multicolumn{11}{|c|}{ Years of experience since graduation } \\
\hline$<5$ & 1 & 33 & 2 & 66.7 & 1 & 33 & 2 & 66.7 & \multirow{2}{*}{$X^{2}=4.107$} & \multirow{2}{*}{$X^{2}=4.107$} \\
\hline 5- & 0 & 0 & 5 & 100 & 0 & 0 & 5 & 100 & & \\
\hline $10-$ & 1 & 5.6 & 17 & 94.4 & 1 & 5.6 & 17 & 94.4 & \multirow{2}{*}{$\mathrm{P}=0.250$} & \multirow{2}{*}{$\mathrm{P}=0.250$} \\
\hline$\geq 15$ & 0 & 0 & 4 & 100 & 0 & 0 & 4 & 100 & & \\
\hline \multicolumn{11}{|c|}{ Received training about infection control } \\
\hline Yes & 1 & 4 & 24 & 96 & 1 & 4 & 24 & 96 & $X^{2}=1.714$ & $X^{2}=1.714$ \\
\hline No & 1 & 20 & 4 & 80 & 1 & 20 & 4 & 80 & $\mathrm{P}=0.190$ & $\mathrm{P}=0.190$ \\
\hline
\end{tabular}

$\mathrm{X}^{2}$ Chi Square Test, * Statistically significant at $\mathrm{p} \leq 0.05$

$\mathrm{P} 1=$ the test of significant pre intervention and immediately after intervention.

$\mathrm{P} 2=$ the test of significant pre intervention and 1month post.

As regard nurses' practice level, it showed statistical significant relationships with nurses' age, their level of education, and nurse's years of experience (Table 5).

Table (5): The relationships between the studied nurses' practice levels and their demographic characteristics after application of the educational intervention (immediately, one month later)

\begin{tabular}{|c|c|c|c|c|c|c|c|c|c|c|}
\hline \multirow{5}{*}{$\begin{array}{l}\text { Socio demographic } \\
\text { characteristics }\end{array}$} & \multicolumn{8}{|c|}{ Nurses' level of practices post intervention } & \multirow{2}{*}{\multicolumn{2}{|c|}{ Test of significance }} \\
\hline & \multicolumn{4}{|c|}{ Immediately } & \multicolumn{4}{|c|}{ One month later } & & \\
\hline & \multirow{2}{*}{\multicolumn{2}{|c|}{$\begin{array}{c}\text { Fair } \\
(N=6)\end{array}$}} & \multirow{2}{*}{\multicolumn{2}{|c|}{$\begin{array}{l}\text { Good } \\
(\mathrm{N}=24)\end{array}$}} & \multirow{2}{*}{\multicolumn{2}{|c|}{\begin{tabular}{l|} 
Fair \\
$(\mathrm{N}=6)$
\end{tabular}}} & \multirow{2}{*}{\multicolumn{2}{|c|}{$\begin{array}{c}\text { Good } \\
(\mathrm{N}=24)\end{array}$}} & \multirow{3}{*}{ P1 } & \multirow{3}{*}{$\mathbf{P 2}$} \\
\hline & & & & & & & & & & \\
\hline & No. & $\%$ & No. & $\%$ & No. & $\%$ & No. & $\%$ & & \\
\hline \multicolumn{11}{|l|}{ Age } \\
\hline $20-$ & 0 & 0.0 & 7 & 100.0 & 0 & 0.0 & 7 & 100.0 & \multirow{2}{*}{$X^{2}=11.090$} & \multirow{2}{*}{$X^{2}=11.090$} \\
\hline $30-$ & 2 & 15.4 & 11 & 84.6 & 2 & 15.4 & 11 & 84.6 & & \\
\hline $40-$ & 4 & 66.7 & 2 & 33.3 & 4 & 66.7 & 2 & 33.3 & \multirow{2}{*}{$\mathrm{P}=0.418^{*}$} & \multirow{2}{*}{$\mathrm{P}=0.418 *$} \\
\hline$\geq 50-$ & 0 & 0.0 & 4 & 100.0 & 0 & 0.0 & 4 & 100.0 & & \\
\hline \multicolumn{11}{|l|}{ Level of education } \\
\hline Technical secondary school & 0 & 0.0 & 1 & 100.0 & 0 & 0.0 & 1 & 100.0 & \multirow{3}{*}{$\begin{array}{l}\mathrm{X}^{2}=8.813 \\
\mathrm{P}=0.284 *\end{array}$} & \multirow{3}{*}{$\begin{array}{l}\mathrm{X}^{2}=8.813 \\
\mathrm{P}=0.284 *\end{array}$} \\
\hline Technical institute & 3 & 75.0 & 1 & 25.0 & 3 & 75.0 & 1 & 25.0 & & \\
\hline Bachelor of nursing & 3 & 12.0 & 22 & 88.0 & 3 & 12.0 & 22 & 88.0 & & \\
\hline \multicolumn{11}{|c|}{ Years of experience since graduation } \\
\hline$<5$ & 0 & 0.0 & 3 & 100.0 & 0 & 0.0 & 3 & 100.0 & \multirow{2}{*}{$X^{2}=2.188$} & \multirow{2}{*}{$X^{2}=2.188$} \\
\hline 5- & 2 & 40.0 & 3 & 60.0 & 2 & 40.0 & 3 & 60.0 & & \\
\hline $10-$ & 3 & 16.7 & 15 & 83.3 & 3 & 16.7 & 15 & 83.3 & \multirow{2}{*}{$\mathrm{P}=0.534$} & \multirow{2}{*}{$\mathrm{P}=0.534$} \\
\hline$\geq 15$ & 1 & 25.0 & 3 & 75.0 & 1 & 25.0 & 3 & 75.0 & & \\
\hline \multicolumn{11}{|c|}{ Received training about infection control } \\
\hline Yes & 6 & 20.7 & 23 & 79.3 & 6 & 20.7 & 23 & 79.3 & $X^{2}=0.259$ & $X^{2}=0.259$ \\
\hline No & 0 & 0.0 & 1 & 100.0 & 0 & 0.0 & 1 & 100.0 & $\mathrm{P}=0.611$ & $\mathrm{P}=0.611$ \\
\hline
\end{tabular}

$\mathrm{X}^{2}$ Chi Square Test, * Statistically significant at $\mathrm{p} \leq 0.05$

$\mathrm{P} 1=$ the test of significant pre intervention and immediately after intervention.

$\mathrm{P} 2=$ the test of significant pre intervention and 1month post. 


\section{DISCUSSION}

The present study results revealed that the majority of the studied nurses' age ranged between twenty to less than forty years. Mukhtad et al. ${ }^{(3)}$, Alnawafleh et al. ${ }^{(15)}$ and Elsaidy et al. ${ }^{(16)}$ reported similar findings.

The present study showed that, the majority of the studied nurses had bachelor degree of nursing. Bachelor nursing graduates, no doubt are more enlightened, adherent, motivated and have higher ability of education. These findings are in line with Alnawafleh et al. ${ }^{(15)}$ and Elsaidy et al. ${ }^{(16)}$. In addition, the majority of the studied nurses were married. Mukhtad et al. ${ }^{(3)}$ however, revealed that the majority of their studied nurses were single.

Also, the majority of the currently studied nurses were females. These findings reflect that nursing in Egypt is still female dominated profession. These results were supported by Mukhtad et al. ${ }^{(3)}$ and Elsaidy et al. ${ }^{(16)}$, who found that, the majority of their studied nurses were females. Alnawafleh et al. ${ }^{(15)}$, however, reported that the majority of their studied nurses were males.

As regards years of experience, the present study results denoted that more than half of the studied nurses had ten to less than 15 years of experience. No doubt, years of experience is considered one of impact factors on nurses' compliance. On the other hand it may be challenging to change nurses' behaviors, as more years of experience may lead nurses to become more resistant to change. Interestingly, Mukhtad et al. ${ }^{(3)}$ and Alnawafleh et al. ${ }^{(15)}$, reported that the majority of their studied nurses, had five years of experience. In addition Elsaidy et al $^{\left({ }^{(16)}\right.}$, reported that more than half of their studied nurses had five years of experience or more.

Concerning attendance of training workshops regarding infection prevention and control practices, the findings of the present study revealed that the majority of the studied nurses attended training workshops, but they were not supplied with the necessary infection control equipment and supplies as reported by many of the studied nurses. These results were supported by Alnawafleh $\boldsymbol{e t}$ al. ${ }^{(15)}$ and Elsaidy $\boldsymbol{e t}$ al. ${ }^{(16)}$ who reported that, more than half of their studied nurses hadn't attended any training workshops related to infection prevention and control practices.

One of the main finding of the present study, is the effects of the educational interventions on nurses overall level of knowledge, as nearly two third of them had "poor" level of knowledge related to infection control practices before application of the nursing interventions, compared to the majority who achieved "high" level of knowledge post interventions (immediately and one month after).

This could be interpreted by the fact that bachelor degree nurses have more extensive undergraduate programs of infection control and microbiology than diploma holder of nursing secondary schools or technical institute. In this context, Vaz et al. (17) reported that education is a potential means for implementing prevention strategies as it alters perception, increases knowledge and in turn changes work practice.

These results were in agreement with Mukhtad et al. ${ }^{(3)}$, Yassin et al. ${ }^{(18)}$ and Nofal et al. ${ }^{(19)}$, who reported that HD nursing staff had "poor" level of knowledge regarding infection control before interventions, and emphasized the importance of training programs.

Regarding immunization of patients and HCPs, the results displayed significant improvement in nurses' knowledge post interventions. Nevertheless, Abdelwahab et al. ${ }^{(20)}$ found that their healthcare staff had "good" knowledge regarding immunization of patients and HCPs.

The current study results had highlighted the overall "poor" nurses' practices of infection prevention and control before application of the educational interventions, as half of the studied nurses had "fair" level of practice and the other half had "poor level" of practice. Interestingly, the majority of the studied nurses achieved "good level" of overall practice immediately, and one month post application of the educational interventions. These results were supported by many researchers, Abdelwahab et al. ${ }^{(20)}$, Morkes et al. $^{\left({ }^{(21)}\right.}$ and Machaly et al. ${ }^{(22)}$.

The present study revealed significant improvement after application of the educational interventions, where all nurses had "good" level of practice of routine hand hygiene, the majority had "good" level related to alcohol hand hygiene and more than three quarters of them had "good" level related to opportunistic hand hygiene.

Similarly, Abdelwahab et al. ${ }^{(20)}$ found that initial hand hygiene compliance rate was "unsatisfactory" by their nurses, which improved significantly after interventions. However, Karkar ${ }^{(12)}$ emphasized that the compliance rate of hand hygiene by their studied HCPs was very "poor". Also emphasized that the minimum number of hand hygiene can be 60 to 100 times required per HD session per patient, one reason for poor of compliance. In line with many other similar studied, "poor" compliance to hand hygiene by nurses was attributed to many factors, as: nursing staff shortage, work load, lack of resources, skin irritation due to frequent hand hygiene, time limits, rapid patient turn over, urgent patients' needs, nonadherence to time table, as well as lack of continuing education ${ }^{(13,16,20,23)}$.

Regarding PPE, the present study findings revealed that the majority of the studied nurses' level of practice was "poor" before interventions, whereas all nurses achieved "good" level of practice after interventions. 
This lie in line with Mukhtad et al. ${ }^{(3)}$, Elsaidy et al. ${ }^{(16)}$ and El-Greeb et al. ${ }^{(24)}$ who reported that nurses' use of PPE was "unsatisfactory" .

The present study findings, are not in line with, Suprapto ${ }^{(25)}$ and Med et al. ${ }^{(26)}$, who reported higher level of compliance of nurses, using PPE. In this regard Refeai et al. ${ }^{(27)}$, stressed that the most frequent barriers were non availability of PPE. They postulated that perhaps nurses supposed that the priority in emergency situations is not donning PPE, but rather providing rapid patient care, assuming that nursing care very difficult. They assumed that work load probably does not give nurses time to use PPE, nurses may feel discomfort with PPE, large number of HD patients and the many procedures needed in one session and the consumed recourses in short time, all these add to the problem.

In relation to arteriovenous fistulas/ arteriovenous grafts (AVF/AVG) cannulation observation and decannulation, the present study showed that half of the studied nurses showed "satisfactory", and "poor" practice levels equally regarding venoarterial (VA) canulation, as well as "satisfactory" levels related to VA decannulation before interventions, that improved after interventions in the majority of the studied nurses, having "satisfactory" level related to AVF/AVG cannulation.

These former findings could be related to the fact that nurses believe that adhere to infection control practices is very important only in decannulation procedure because of body fluid exposure, so they prefer to protect themselves rather than protecting their patients. This result was in line Elsaidy et al. ${ }^{(16)}$, who found that the nurses had "satisfactory" level of practice regarding aseptic techniques during cannulation and decannulation of VA. Moursy and Sharaf ${ }^{(11)}$ however, reported that their nurses had "poor" level of practice during cannulation and decannulation of VA care.

The present study revealed that the studied nurses had "satisfactory" level of practice regarding catheter connection and disconnection and catheter exit site care before education, which has improved to "good" level of practice after the education. Many nurses frequently care for catheter connection and disconnection and catheter exit site aseptically since dialysis catheters have infection rates higher than AVF /AVG (10 times higher) ${ }^{(\mathbf{1 2}, \mathbf{2 0})}$.

The present study revealed that there was no statistical significant relationship between nurses' knowledge levels and their sociodemographic data after application of the educational interventions (immediately, one month later). These findings are not in line with Shah et al. ${ }^{(6)}$ and Machaly et al. ${ }^{(22)}$, who demonstrated a statistical significant relationship between the studied nurses' total mean knowledge scores and their years of experience.
A statistical significant relationship was identified between nurses practice levels and their level of education. This result was supported by Moursy and Sharaf ${ }^{(11)}$ who found that nurses with bachelor degree had significantly higher mean percent score practice than those with diploma degree. Elsaidy et al. (16) however, reported that no statistical significant relationship was identified between nurses practice levels and their level of education. Also, Bayoumi and Mahmoud ${ }^{(28)}$, found a high statistical significant positive correlation between nurses' practice and their educational level.

The present study revealed no statistical significant relations between the current nurses' years of experience, receiving former training, and their practice levels. This result is not in line with Machaly et al. (22), who found that there was a statistical significant relationship between nurses' overall practice and their years of experiences. Also, Bayoumi and Mahmoud (28) found that years of experience and attendance of training courses had significantly improved nurses' practice levels, after education.

\section{CONCLUSION}

Based on the results of this study, the study hypotheses were approved, as the educational nursing interventions had significant positive effects on overall percent improvement of nurses' knowledge, and practice related to infection control in HD Unit, Fever Hospital, Alexandria. Statistical significant relationships were detected between the nurses' age, level of education, and their practices level. No statistical significant relationships were detected between the studied nurse's sociodemographics, and their knowledge's level.

\section{RECOMMENDATIONS}

A. Recommendations for nurse managers:

- Supervise the staff nurses practice of infection prevention and control standards

- Monitor nursing adherence to policies of the hospital.

- Promote feedbacks on practice.

B. Recommendations for administrators:

- Regular infection prevention and control educational programs for HD nurses.

- Provision of standards and procedure manuals on infection prevention and control measure at HD units is mandatory.

- Policies and infection prevention and control procedures at HD units should be reviewed and updated to ensure strict implementation and compliance to infection prevention and control guidlines.

- Reward and punishment system should be applied. 


\section{EFERENCES}

1. Kramer A, Boenink R, Stel $V$ et al. (2021): The ERAEDTA Registry Annual Report 2018: a summary. Clinical Kidney Journal, 14(1): 107-123.

2. Ahamed S, Sallam S (2018): The effect of nursing instructions on nurses' knowledge, practice and suggestions regarding adverse events in hemodialysis. American Journal of Nursing Research, 6(5): 237-243.

3. Mukhtad A, Alfahkry R, Mousa W et al. (2019): Assessment of Knowledge, Attitudes and Practices of Nurses Regard Infection Control Program in El-Hawwary Renal Dialysis Centre in Benghazi City, Libya. International Journal of Advances in Nephrology Research, 19: 1-10.

4. Karkar A (2018): Infection control guidelines in hemodialysis facilities. Kidney Research and Clinical Practice, 37(1): 1-6.

5. Teymourzadeh E, Bahadori M, Fattahi $H$ et al. (2019): Nurses' competency and their role in prevention and control of hospital infections: A case study in a large military teaching hospital. Advances in Human Biology, 9(2): 15662.

6. Shah M, Mehtab R, Ullah W et al. (2020): Nurses awareness regarding prevention of nosocomial infections in critical care areas of tertiary care hospital Peshawar, KPK. Nursing and Healthcare, 2(10): 76-83.

7. Hinkle J, Cheever K (2014): The $13^{\text {th }}$ edition of Brunner \& Suddarth's Textbook of Medical-Surgical Nursing. Lippincott, Williams \& Wilkins, Philadelphia, Pa. https://www.researchgate.net/publication/259563851_Hinkle _JL_Cheever_K_2014_The_13th_edition_of_Brunner_Sudd arth's_Textbook_of_Medical-

Surgical_Nursing_Lippincott_Williams_Wilkins_Philadelph ia_Pa

8. Center of disease control and prevention (2016): Core interventions. Atlanta, GA: CDC. Available at https://www.cdc.gov/antibiotic-use/coreelements/hospital.html

9. Patel P, Brinsley-Rainisch K (2018): The making dialysis safer for patients coalition: a new partnership to prevent hemodialysis-related infections. Clinical Journal of the American Society of Nephrology, 13(1): 175-181.

10. Palmer S, de Berardis G, Craig J et al. (2014): Patient satisfaction with in-centre haemodialysis care: an international survey. British Medical Journal Publishing Group, 4(5): 5020-25.

11. Moursy A, Sharaf A (2017): Vascular access care at hemodialysis unit; nurses compliance to infection prevention and control practices. IORS Journal of Nursing and Health Science, 6(2): 6-10.

12. Karkar A (2016): Hand hygiene in haemodialysis units. Open Access Library Journal, 3(08): 1-5.

13. Patel P, Sarah H, Booth S et al. (2013): Bloodstream infection rates in outpatient hemodialysis facilities participating in a collaborative prevention effort: a quality improvement report. American Journal of Kidney Diseases, 62(2): 322-330.

14. World Health Organization (2018): Moments for hand hygiene: Geneva, Switzerland, WHO. https://www.who.int/gpsc/5may/tools/who_guidelineshandhygiene_summary.pdf

15. Alnawafleh K, Mohammad Z, Al-Nwafleh H (2018): Auditing of nursing care for hemodialysis patients at $\mathrm{Ma}$, an
Governmental Hospitals-Jordan. Assiut Scientific Nursing Journal, 6(15): 89-98.

16. Elsaidy Z, Weheida S, Zaki S et al. (2019): Risk factors exposing hemodialysis patients to blood borne infections. (Master thesis): Faculty of Nursing. http://main.eulc. edu.eg/eulc_v5/Libraries/Thesis/BrowseThesisPages.aspx?fn $=$ PublicDrawThesis $\&$ BibID $=12626034$

17. Vaz K, McGrowder D, Alexander-Lindo $\mathrm{R}$ et al. (2010): Knowledge, awareness and compliance with universal precautions among health care workers at the University Hospital of the West Indies, Jamaica. The international Journal of Occupational and Environmental Medicine, 1(4): 171-181.

18. Yassin S, Soliman M, Hoda I et al. (2018): Assessment of Infection Control Knowledge and Practices among Hemodialysis Nursing Staff in Kasr Al-Ainy Hospitals. The Medical Journal of Cairo University, 86: 1649-1656.

19. Nofal M, Subih M, Al-Kalaldeh M et al. (2017): Factors influencing compliance to the infection control precautions among nurses and physicians in Jordan: A cross-sectional study. Journal of Infection Prevention, 18(4): 182-188.

20. Abdelwahab M, Labah E, Sayed L et al. (2019): Impact of infection prevention and control education program on improving knowledge, attitude and practices of the healthcare staff in hemodialysis unit at Egyptian tertiary care facility. Asian Journal of Medicine and Health, 14(4): 1-11.

21. Morkes S, Abozead S, Azer S (2018): effect of educational program on nurses performance about infection control for patients undergoing hemodialysis. Assiut Scientific Nursing Journal, 6(15): 162-168.

22. Machaly E, Bahgat $\mathrm{R}$, Hassan $\mathrm{H}$ et al. (2020): Effect of implementing evidence based nursing guidelines on nurses' performance about care provided for children undergoing hemodialysis. Journal of Nursing and Health Sciences, 9(3): 21-28.

23. Prathibha J, Lobo D, Nayak $\mathbf{S}$ et al. (2020): Practice and perceived barriers among health care workers to control infection in dialysis unit. Medico Legal Update, 20(1): 165169.

24. El-Greeb H, Amel I, Hussien M et al. (2018): Assessment of nurses' compliance with infection control standard precautions at outpatient clinics of Urology and Nephrology Center-Mansur University. Journal of Nursing and Health Sciences, 7(3): 54-59.

25. Suprapto $\mathbf{S}$ (2020): Nurse compliance using basic personal protective equipment in providing health services nursing actions. International Journal of Medicine and Public Health, 10(3): 119-121.

26. Med M, Pedro Pallangyo M, Med M (2020): Adherence to universal precautions and associated factors among nurses caring for critically ill patients in Dar es Salaam Tanzania. Journal of Nursing and Health Care, 3(3): 106-113.

27. Refeai S, Kamal N, Ghazawy E et al. (2020): Perception and barriers regarding infection control measures among healthcare workers in Minia city, Egypt. International Journal of Preventive Medicine, 11:1-6.

28. Bayoumi M, Mahmoud N (2017): Effect of education program on nurses' knowledge and practice regarding care of central venous line in pediatric hemodialysis: evidencebased practice guidelines. Egyptian Nursing Journal, 14(2):87-92. 